\title{
Detection and Partial Characterization of an Inhibitor of Plasminogen Activator in Human Platelets
}

\author{
Larry A. Erickson, Mark H. Ginsberg, \\ and David J. Loskutoff \\ Department of Immunology, Scripps Clinic and Research \\ Foundation, La Jolla, California 92037
}

bstract. In this study, we demonstrate the presence of a previously undescribed fibrinolytic inhibitor in human serum. It has an apparent molecular weight of 50,000 and is not detected in serum derived from platelet-poor plasma, suggesting that it originates from platelets. This conclusion is supported by a number of observations. For example, extracts of washed, gel-filtered human platelets contain an inhibitor of similar activity and size, and physiological concentrations of thrombin induce its release from the platelets. Moreover, the kinetics and dose dependency of this release are similar to those observed for the release of platelet factor 4 , and the release of both molecules is blocked by pretreating the platelets with prostaglandin $E_{1}$ and theophylline. Mixing experiments, which were devised to investigate the specificity of the inhibitor, showed that the fibrinolytic activity initiated by both urokinase and tissue-type plasminogen activator was blocked by platelet releasate in a dose-dependent manner. In both cases, the amount of inhibition increased when the releasates were preincubated with the purified activators, indicating a direct interaction between the activators and an inhibitor(s). The inhibitory activity was removed by preincubating the releasates with antiserum prepared against an antiactivator purified from cultured bovine aortic endothelial cells. These results indicate that platelets contain an inhibitor which is released by thrombin, inhibits both urokinase and tissue-type plasminogen activator, and is immunologically similar to an inhibitor produced by

This is publication no. 3287-IMM from the Scripps Clinic and Research Foundation.

Address all correspondence to Dr. Loskutoff.

Received for publication 29 March 1984 and in revised form 31 May 1984.

J. Clin. Invest.

(c) The American Society for Clinical Investigation, Inc. 0021-9738/84/10/1465/08 $\$ 1.00$

Volume 74, October 1984, 1465-1472 endothelial cells. This molecule may represent a new class of inhibitors, the antiactivators, which function together with $\alpha_{2}$-antiplasmin to regulate the fibrinolytic system of the blood. Its release from platelets by thrombin may protect the growing thrombus against premature dissolution initiated by plasminogen activators released by the endothelium.

\section{Introduction}

The vascular fibrinolytic system is regulated by factors that influence the formation of plasmin, the primary fibrinolytic enzyme of the blood (1). A number of recent observations indicate that plasmin formation is initiated by the release of tissue-type plasminogen activator (t-PA) ${ }^{1}$ from the endothelium $(2,3)$. Whereas the activity of this molecule may be regulated by fibrin itself $(4,5)$, the activity of circulating plasmin is influenced both by fibrin (6) and by $\alpha_{2}$-antiplasmin, its primary physiologic inhibitor (7). Although inhibitors of PA may be expected to modulate this system as well, their existence in plasma from normal donors has been difficult to demonstrate (8). However, a number of more recent reports suggest the existence of such anti-PA activities in the plasma of certain individuals (9-11). Elucidation of the origin, specificity, and biochemical nature of these molecules has been hampered both by the complexity of the blood and by the lack of assays specific for anti-PAs.

We have developed a new technique, reverse fibrin autography (RFA; 12, 13), to detect fibrinolytic inhibitors in complex biological samples after their fractionation by sodium dodecyl sulfate-polyacrylamide gel electrophoresis (SDS-PAGE). This approach was employed successfully to demonstrate the existence of several fibrinolytic inhibitors in bovine serum (13). Here we show that human serum also contains such an

1. Abbreviations used in this paper: BAE, bovine aortic endothelial cells; CM, conditioned medium; MEM, minimum essential medium; PF-4, platelet factor 4; $P G E_{1}$, prostaglandin $E_{1}$; PPP, platelet-poor plasma; PRP, platelet-rich plasma; RFA, reverse fibrin autography; SDS-PAGE, sodium dodecyl sulfate-polyacrylamide gel electrophoresis; t-PA, tissue-type plasminogen activator. 
inhibitor, and present evidence that it originates from platelets and is an antiactivator.

\section{Methods}

Preparation of plasma and serum. Whole human blood was collected into polypropylene tubes containing $3.8 \% \mathrm{Na}$ citrate, pH 7.4 and centrifuged at $1,000 \mathrm{rpm}$ for $15 \mathrm{~min}$ at $23^{\circ} \mathrm{C}$ to obtain platelet-rich plasma (PRP). The PRP was chilled to $4^{\circ} \mathrm{C}$ for $15 \mathrm{~min}$ and then centrifuged at $3,000 \mathrm{rpm}$ for $30 \mathrm{~min}$ at $4^{\circ} \mathrm{C}$ to obtain platelet-poor plasma (PPP). Serum was obtained by incubating the PRP and PPP at $37^{\circ} \mathrm{C}$ for $10 \mathrm{~min}$ before the addition of $\mathrm{CaCl}_{2}(6 \mathrm{mM})$. After an additional $2 \mathrm{~min}$ at $37^{\circ} \mathrm{C}$, thrombin $(2.5 \mathrm{U} / \mathrm{ml})$ was added and the mixtures were incubated for $30 \mathrm{~min}$ at $37^{\circ} \mathrm{C}$ and then for $5 \mathrm{~min}$ at $4^{\circ} \mathrm{C}$. The clots were removed by centrifugation and the resultant supernatants were collected and stored at $-20^{\circ} \mathrm{C}$ until used.

The inhibitor in PRP serum $(5 \mathrm{ml})$ was partially purified by passing the serum over a $1 \mathrm{ml}$ concanavalin A-Sepharose (Pharmacia, Uppsala, Sweden) column. Analysis by SDS-PAGE revealed that the majority of the serum albumin was found in the run-through material. The protein that bound to the column was eluted at a flow rate of $1 \mathrm{ml} / \mathrm{h}$ with $0.5 \mathrm{M} \alpha$-methyl-D-mannoside (Sigma Chemical Co., St. Louis, $\mathrm{MO}$ ) in $0.01 \mathrm{M}$ phosphate buffer, $\mathrm{pH} 7.2$, containing $1 \mathrm{M} \mathrm{NaCl}, 0.01 \%$ Tween 80 (J. T. Baker Chemical Co., Phillipsburg, NJ), and $0.02 \%$ sodium azide. Fractions containing the inhibitor as determined by RFA (see below) were pooled and used as "albumin-depleted" serum.

Release of platelet constituents. Gel-filtered platelets were prepared from human PRP according to the method of Ginsberg et al. (14). Briefly, platelets were obtained from PRP as outlined above and then passed over an acetone-washed Sepharose CL-2B (Pharmacia) column equilibrated in Hepes-Tyrodes buffer, $\mathrm{pH} 7.35$, containing $1 \mathrm{mg} / \mathrm{ml}$ bovine serum albumin (Calbiochem-Behring Corp., San Diego, CA). The platelets were counted with a Coulter counter (Coulter Electronics, Inc., Hialeah, FL) and diluted with Hepes-Tyrodes buffer, $\mathrm{pH}$ 6.5, to a concentration of $1 \times 10^{9}$ platelets $/ \mathrm{ml}$. The platelets either were lysed with $0.1 \%$ Triton X-100 (Sigma Chemical Co.) or incubated in buffer containing increasing concentrations of thrombin for various times. After incubation, the samples were centrifuged at $3,000 \mathrm{rpm}$ for 30 min at $4^{\circ} \mathrm{C}$ to remove the platelets and obtain platelet releasates. In certain experiments, prostaglandin $\mathrm{E}_{1}\left(\mathrm{PGE}_{1}, 1 \mu \mathrm{g} / \mathrm{ml}\right)$ and theophylline $(0.9 \mathrm{mM})$ were added to the platelets prior to the thrombin.

Cell culture. Bovine aortic endothelial cells (BAEs) were isolated and maintained in vitro in modified minimum essential medium (MEM; Flow Laboratories, Inglewood, CA) containing 10\% calf serum (Irvine Scientific, Santa Ana, CA, or Sterile Systems Inc., Logan, UT) as indicated (15). The cells used for these studies were cloned from a single cell (16) and had been passaged 5-20 times. All cultures were grown to confluency in 60-mm dishes (Falcon Labware, Oxnard, CA) before use. Conditioned medium (CM) was prepared by incubating cell monolayers previously washed two times with warm MEM, in serum-free MEM for $24 \mathrm{~h}$. This CM was collected, centrifuged at 1,000 $g$ to remove floating cells and cellular debris, and stored in $0.01 \%$ Tween 80 at $-20^{\circ} \mathrm{C}$ until used.

SDS-PAGE. SDS-polyacrylamide slab gels and buffers were prepared as described by Laemmli (17). Samples were applied to gels composed of $10-\mathrm{cm}$ resolving gels of $9 \%$ acrylamide and $2-\mathrm{cm}$ stacking gels of $4 \%$ acrylamide, and then subjected to electrophoresis at room temperature for $16 \mathrm{~h}$ or until the dye reached the bottom of the gel. Gels were analyzed by RFA, or stained with $0.1 \%$ Coomassie Blue (BioRad Laboratories, Richmond, CA) and destained with $10 \%$ acetic acid.
$R F A$. Fibrin-agar indicator films were prepared essentially as described (13). Briefly, agarose (final concentration, 1\%; LPG agarose, Miles Laboratories) was mixed with prewarmed $\left(45^{\circ} \mathrm{C}\right)$ phosphatebuffered saline (PBS; $0.14 \mathrm{M} \mathrm{NaCl}, 0.01 \mathrm{M} \mathrm{Na}$ phosphate, pH 7.2) containing plasminogen (final concentration, $25 \mu \mathrm{g} / \mathrm{ml}$ ) and thrombin (final concentration, $0.5 \mathrm{U} / \mathrm{ml}$ ). Bovine fibrinogen (final concentration, $2.4 \mathrm{mg} / \mathrm{ml}$; plasminogen and thrombin-free; Calbiochem-Behring Corp.) in PBS $\left(37^{\circ} \mathrm{C}\right)$ containing urokinase $(0.025 \mathrm{U} / \mathrm{ml}$ final concentration) was added and the solution was poured onto a prewarmed $\left(45^{\circ} \mathrm{C}\right)$ glass plate. After electrophoresis, the polyacrylamide gels were soaked in $250 \mathrm{ml}$ of $2.5 \%$ Triton X-100 ( 2 changes, 45 min each) to neutralize the SDS and placed on the surface of the fibrin-agar indicator film. The gel and indicator were incubated in a moist chamber for $2 \mathrm{~h}$ at $37^{\circ} \mathrm{C}$ and then photographed.

${ }^{125}$ I-Fibrin plate assay of inhibitory activity. The antifibrinolytic activity of platelet samples was determined by the ${ }^{125}$ I-fibrin plate assay as described $(18,19)$. Various amounts of releasate were preincubated with urokinase $(0.025 \mathrm{U} / \mathrm{ml})$ or t-PA $(0.025 \mathrm{U} / \mathrm{ml})$ for varying periods

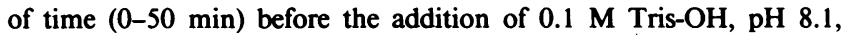
containing $4 \mu \mathrm{g}$ of plasminogen and $0.1 \%$ gelatin to a final volume of $1 \mathrm{ml}$. In each instance, residual PA activity was then measured by quantitating the amount of radiolabeled fibrin released from the bottom of the culture well. The assays were terminated when the untreated PA samples hydrolyzed $15-25 \%$ of the total ${ }^{125}$ I-fibrin as determined by direct comparison to the release of $100 \%$ of the labeled fibrin by trypsin $(50 \mu \mathrm{g} / \mathrm{ml}, 1 \mathrm{~h}$; Gibco, Grand Island, NY).

Immunoadsorption of the inhibitor activity in BAE CM and platelet releasate. Protein A-Sepharose CL-4B (Pharmacia) was rehydrated in PBS containing $0.1 \%$ bovine serum albumin, $0.05 \%$ Tween 20 (J. T. Baker Chemical Co.), and $0.02 \%$ sodium azide. Antiserum (40 $\mu \mathrm{l})$ against an inhibitor purified from BAE CM (20) (van Mourik, J., D. Lawrence, and D. J. Loskutoff, manuscript submitted for publication) and nonimmune rabbit serum $(40 \mu \mathrm{l})$ were separately incubated with $100 \mu \mathrm{l}$ of the suspension (representing $\sim 3 \mu \mathrm{g}$ of coupled Sepharose beads) for $15 \mathrm{~min}$ at $23^{\circ} \mathrm{C}$. The beads were washed three times with buffer, and BAE CM $(500 \mu \mathrm{l})$ or platelet releasate $(200 \mu \mathrm{l}$, representing $4 \times 10^{8}$ platelets) was added. The mixtures were incubated for $1 \mathrm{~h}$ at $23^{\circ} \mathrm{C}$ and then centrifuged at $1,000 \mathrm{rpm}$ for $5 \mathrm{~min}$. The resultant supernatants and pellets were extracted with sample buffer and the extracts fractionated by SDS-PAGE and analyzed by RFA. In addition, an immunoadsorbent column $(1.5 \mathrm{~cm} \times 3.4 \mathrm{~cm})$ was prepared as described (21) using $10 \mathrm{ml}$ of CNBr-activated Sepharose CL-4B (Pharmacia) and $40 \mathrm{ml}(0.5 \mathrm{mg} / \mathrm{ml})$ of the $\mathrm{IgG}$ fraction of the antiserum to the BAE inhibitor. Platelet releasate $\left(165 \mathrm{ml}\right.$, representing $3.3 \times 10^{11}$ platelets) was passed over this column at a flow rate of $2 \mathrm{ml} / \mathrm{h}$, the column was washed at $10 \mathrm{ml} / \mathrm{h}$ with PBS containing $1 \mathrm{M} \mathrm{NaCl}$, and the adsorbed material was eluted at $10 \mathrm{ml} / \mathrm{h}$ with $3 \mathrm{M} \mathrm{MgCl}_{2}$ in PBS, $0.01 \%$ Tween 80 . Both the excluded and bound material then were assayed for inhibitor activity by RFA and by the ${ }^{125}$ I-fibrin plate assay described above.

Quantitation of platelet factor 4 (PF-4). The amount of PF-4 antigen in the platelet releasates was determined by radioimmunoassay as described previously (22).

Materials. Plasminogen was prepared by affinity chromatography on lysine-Sepharose as described (23). Plasmin was obtained by activating plasminogen (final concentration, $900 \mu \mathrm{g} / \mathrm{ml}$ ) with urokinase (final concentration, $190 \mathrm{U} / \mathrm{ml}$ ) in $50 \%$ glycerol for $24 \mathrm{~h}$ at $37^{\circ} \mathrm{C}$. Human $\alpha$-thrombin was a generous gift from J. Fenton (New York State Dept. of Health, Albany, NY). Purified human urokinase containing both 55,000 and 33,000 molecular weight forms (World Health Organization 
standard) was supplied by A. Johnson (New York University). Human t-PA was purified from cultured human melanoma cells grown in the presence of Trasylol (Calbiochem-Behring Corp.) according to the procedure of Rijken and Collen (24). It had a specific activity of $125,000-150,000 \mathrm{U} / \mathrm{mg}$ of protein and consisted primarily of the single-chain molecule. The IgG fraction of rabbit antiserum to the inhibitor purified from BAE CM was prepared as described (16). PGE and theophylline were purchased from Sigma Chemical Co. Molecular weight standards were obtained from Bio-Rad Laboratories and included carbonic anhydrase $(31,000)$, ovalbumin $(45,000)$, and bovine serum albumin $(66,200)$.

\section{Results}

Detection of fibrinolytic inhibitors in human serum and platelets. We previously employed RFA to detect and partially characterize the SDS-stable fibrinolytic inhibitors present in bovine serum (13). After SDS-PAGE, these molecules were revealed by the appearance of opaque lysis-resistant zones in an otherwise lysed fibrin indicator film. Fig. 1 demonstrates that human serum obtained from PRP also contained one such inhibitor (lane 1). Unexpectedly, PPP (not shown) and serum from PPP (lane 2) did not contain inhibitor activity, suggesting that the inhibitor originated from the platelets. To test this possibility, we prepared Triton X-100 extracts of gel-filtered platelets and analyzed them by SDS-PAGE and RFA (lane 4). Although an inhibitor was detected in these extracts, it migrated more slowly than the inhibitor seen in the serum obtained from PRP (lane 1). The relative mobility of some serum proteins is distorted by the high concentration of albumin present (25) (Erickson, L. A., M. H. Ginsberg, and D. J. Loskutoff, unpub-

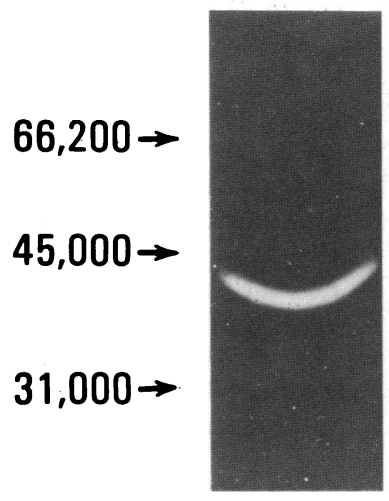

1

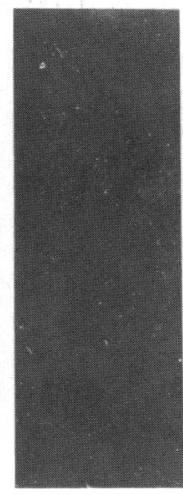

2

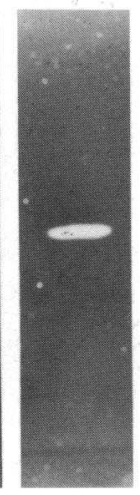

3

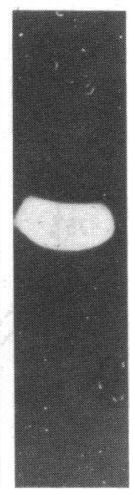

4
Figure 1. Detection of fibrinolytic inhibitors in human serum and platelets. Human serum and an extract of gel-filtered human platelets were subjected to SDS-PAGE and analyzed by RFA as described in Methods. The indicator film was photographed after 2-h incubation at $37^{\circ} \mathrm{C}$. The positions of molecular weight standards are indicated. Lane 1, PRP serum ( $25 \mu \mathrm{l})$; lane 2, PPP serum ( $25 \mu \mathrm{l})$; lane 3 , the concanavalin A-binding fraction of PRP serum $(75 \mu \mathrm{l})$; lane 4 , Triton $\mathrm{X}-100$ platelet extract $\left(50 \mu \mathrm{l}\right.$, representing $5 \times 10^{7}$ platelets). lished observations). Thus, we removed the albumin from PRP serum by passage over a concanavalin A-Sepharose column. The serum inhibitor eluting from this column (lane 3) now comigrated with the platelet inhibitor (lane 4).

Release of the inhibitor from platelets. The results presented above suggest that the inhibitor detected in human serum was released from platelets during clot formation. To test this possibility directly, we examined the ability of thrombin to induce the release of the inhibitor from gel-filtered platelets (Fig. 2). The inhibitor present in extracts prepared from these platelets is shown in lane one. Thus, this zone of inhibition represents $100 \%$ of the potential releasable inhibitor activity present in these platelets. No inhibitor was detected in the releasate obtained from platelets incubated with buffer only (lane 2). However, it was present in releasates prepared from thrombin-treated platelets (lanes 4-6). The amount of inhibitor released from the platelets by thrombin increased in a dosedependent manner, with maximal release being achieved with $0.1 \mathrm{U} / \mathrm{ml}$ of thrombin (lane 5). Thrombin did not release inhibitor from platelets previously treated with $P_{G E}$ and theophylline (lane 7). These results were confirmed when the same samples were analyzed for inhibitory activity by using the more quantitative ${ }^{125} \mathrm{I}$-fibrin plate assay (Fig. 3). Again, release of inhibitory activity was maximal with $0.1 \mathrm{U} / \mathrm{ml}$ of thrombin and was blocked by $\mathrm{PGE}_{1}$ and theophylline. The

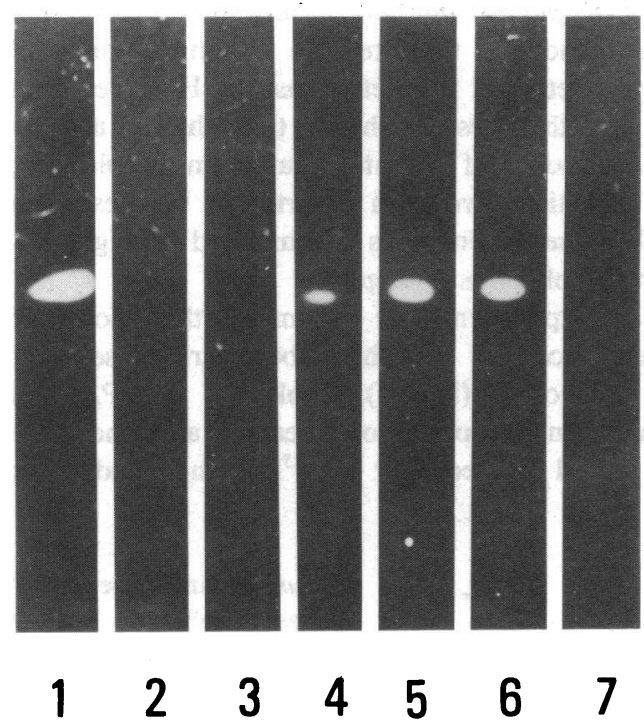

Figure 2. Release of the inhibitor from platelets by thrombin. The soluble portion of a platelet extract $\left(50 \mu \mathrm{l}\right.$, representing $5 \times 10^{7}$ platelets) was analyzed by RFA as described in Methods (lane 1). Lanes 2-6 show the releasates (50 $\mu$, representing $5 \times 10^{7}$ platelets) from platelets treated with 0 (buffer only), $0.01,0.05,0.1$, or $0.5 \mathrm{U} /$ $\mathrm{ml}$ of thrombin, respectively. The releasate in lane 7 was obtained from platelets treated with $0.5 \mathrm{U} / \mathrm{ml}$ of thrombin in the presence of 1 $\mu \mathrm{g} / \mathrm{ml} \mathrm{PGE} \mathrm{P}_{1}$ and $0.9 \mathrm{mM}$ theophylline. The indicator film was photographed after 2-h incubation at $37^{\circ} \mathrm{C}$. 


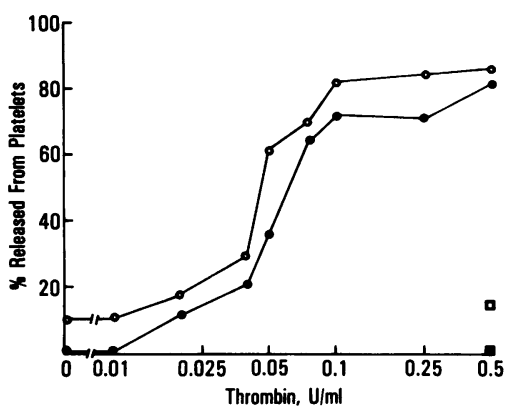

Figure 3. Quantitation of the release of inhibitor and PF-4 from platelets. Releasates prepared from platelets treated with increasing concentrations of thrombin were assayed for inhibitor activity on ${ }^{125}$ I-fibrin plates $(\bullet)$ and for PF-4 by radioimmunoassay (0). In both instances, the amount of released material was expressed as a percent of the total potential releasable activity or antigen as determined by assaying whole platelet extracts. Releasates prepared from platelets pretreated with $\mathrm{PGE}_{1}(1 \mu \mathrm{g} / \mathrm{ml})$ and theophylline $(0.9 \mathrm{mM})$ were also tested for inhibitor ( $($ ) and PF-4 (口).

release of PF-4 from the same platelets closely paralleled the release of inhibitory activity in that its maximal release also was achieved with $0.1 \mathrm{U} / \mathrm{ml}$ of thrombin and was blocked by $\mathrm{PGE}_{1}$ and theophylline. In addition, the kinetics of the release of inhibitory activity and PF-4 were similar (Fig. 4). Release of both molecules was complete within $30 \mathrm{~s}$ at $37^{\circ} \mathrm{C}$ in the presence of $1 \mathrm{U} / \mathrm{ml}$ of thrombin. Similar results were obtained when the kinetics of inhibitor release were determined by RFA (not shown).

Specificity of the platelet inhibitor. The results presented in Figs. 1-3 clearly indicate the presence of an inhibitor of fibrinolysis in platelets and platelet releasates. However, it is not at all clear from these results whether this inhibitor activity results from the presence of an antiactivator, an antiplasmin, or both. Both activities have been reported to be present in platelets (26-28). The experiments summarized in Figs. 5-8 were designed to resolve this ambiguity.

In preliminary experiments, we determined the amount of platelet releasate necessary to inhibit both urokinase- and t-PA-mediated fibrinolysis (Fig. 5). Urokinase or t-PA was mixed with increasing amounts of releasate and then the mixtures were added immediately to ${ }^{125}$ I-fibrin-coated wells

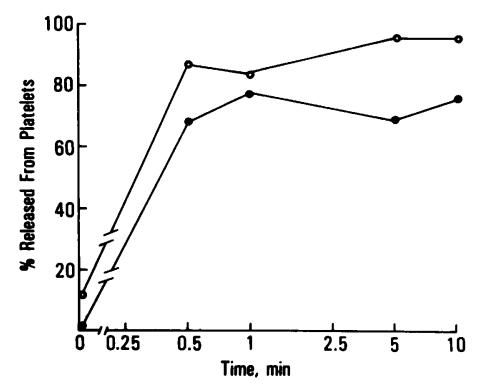

Figure 4. Time-dependent release of inhibitory activity and PF-4. Gel-filtered platelets $\left(1 \times 10^{9} / \mathrm{ml}\right)$ were incubated with buffer only or thrombin $(1 \mathrm{U} / \mathrm{ml})$ for various times. Each sample was then centrifuged and the supernatants were collected and assayed for either inhibitory activity (๑)

or PF-4 (o) as described in the legend to Fig. 3. The data are expressed as a percentage of the total potential activity or antigen recovered from the platelet extracts.

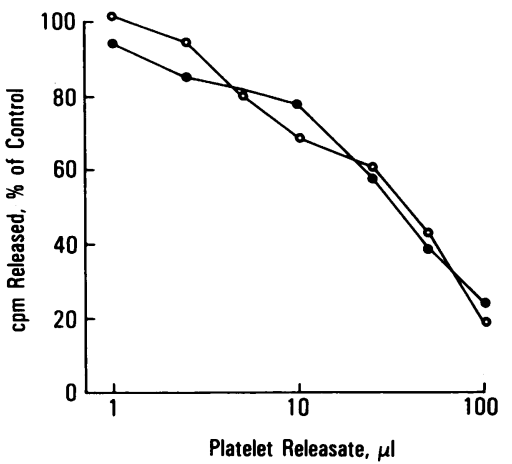

Figure 5. Dose-dependent inhibition of PAinduced fibrinolytic activity by platelet releasate. Increasing amounts of releasate were added simultaneously with urokinase (๑) or t-PA (o) to ${ }^{125}$ I-fibrin-coated wells containing plasminogen $(4 \mu \mathrm{g} / \mathrm{ml})$. The amount of residual fibrinolytic activity was then determined as described in Methods.

containing plasminogen. In both cases, a dose-dependent decrease in fibrinolysis was observed, with $50 \%$ inhibition occurring in the presence of $\sim 50 \mu \mathrm{l}$ of releasate (representing 1 $\times 10^{8}$ platelets). To determine if the releasates actually contained anti-PA activity, we assessed whether the extent of inhibition increased upon preincubation of the PA and releasate (Fig. 6). $10 \mu \mathrm{l}$ of releasate, which inhibited fibrinolysis by only $20-30 \%$ when added to plasminogen simultaneously with PA (Fig. 5), inhibited fibrinolysis by over $50 \%$ after 10 -min preincubation and by over $80 \%$ after 50 -min preincubation. This increase in the extent of inhibition upon preincubation of the releasate and PA suggests a direct, time-dependent interaction between the PAs and a molecule(s) in the releasate.

In separate experiments, we attempted to measure the antiplasmin activity of the releasate. As shown above (Fig. 5), $100 \mu \mathrm{l}$ of releasate (representing $2 \times 10^{8}$ platelets) inhibited the fibrinolytic activity initiated by $0.0025 \mathrm{U}$ of urokinase or

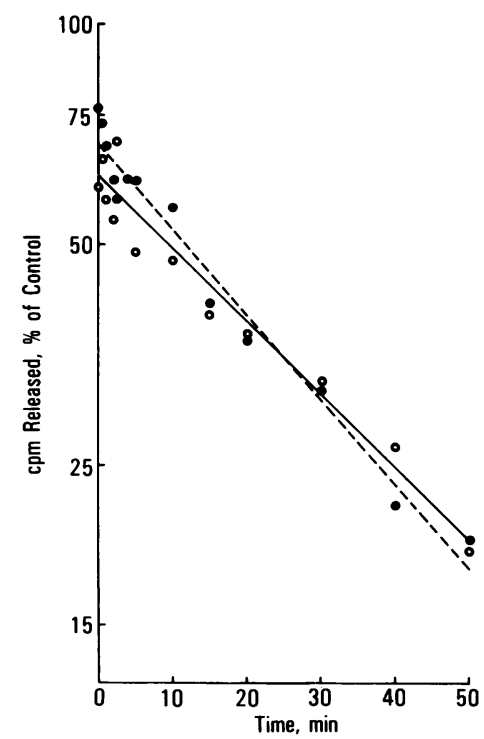

Figure 6. Time-dependent inhibition of PA activity by platelet releasate. Platelet releasate (representing 2 $\times 10^{7}$ platelets) was preincubated with urokinase (-- --) or t-PA (-O-) for various times. Plasminogen was added and the fibrinolytic activity of the samples was determined in the ${ }^{125} \mathrm{I}$ fibrin plate assay as described. At each time point, the amount of fibrinolytic activity generated by PA preincubated with the releasate is expressed as a percentage of that generated by PA preincubated in the presence of buffer only. 
t-PA by $\sim 80 \%$. Under similar conditions, this same amount of releasate did not inhibit an amount of plasmin (10 ng), which exhibited the same fibrinolytic activity as the mixture of PA and plasminogen. Moreover, $950 \mu$ l of platelet releasate (representing $\sim 2 \times 10^{9}$ platelets), which inhibited the fibrinolytic activity initiated by $10 \mathrm{ng}$ of urokinase by $\sim 90 \%$, only inhibited $10 \mathrm{ng}$ of plasmin by $20 \%$ (data not shown).

The anti-PA activity described above was detected in whole, unfractionated platelet releasates. Thus, the identity of the component(s) responsible for this inhibition was not apparent. The following set of experiments was designed to address this question. Specifically, we wondered whether antiserum against the inhibitor synthesized by BAEs (20) (van Mourik, J., D. Lawrence, and D. J. Loskutoff, manuscript submitted for publication) could recognize the platelet inhibitor, and thus, be used to remove it from platelet releasates. As shown in Fig. 7, the BAE and platelet inhibitors comigrate in SDS-polyacrylamide gels. The $\operatorname{BAE~} \operatorname{CM}(A$, lane 1$)$ and platelet releasate $(B$, lane 1$)$ were then incubated with the anti-BAE inhibitor serum as described in the Methods section. After centrifugation, the respective supernatants (lane 2) and immunoprecipitates (lane 3) were analyzed for inhibitor activity
A
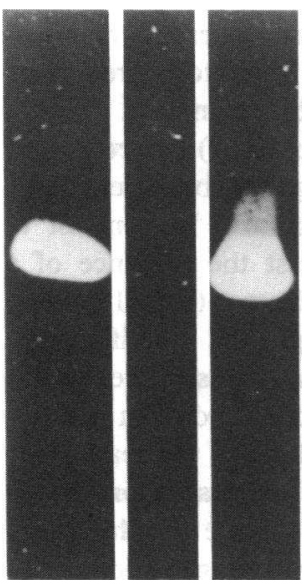

12
B

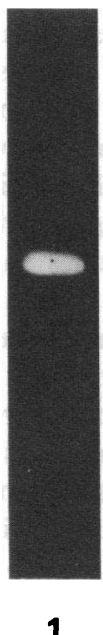

1

2
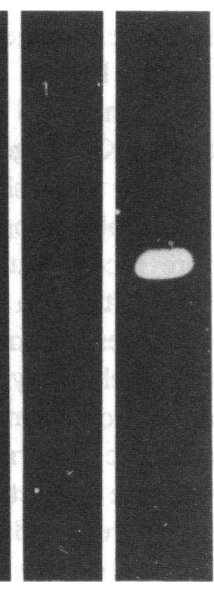

3
Figure 7. Immunoprecipitation of the inhibitors in BAE CM and platelet releasate. The $\mathrm{IgG}$ fraction of the antiserum $(40 \mu \mathrm{l})$ against the BAE inhibitor was coupled to protein A-Sepharose $(3 \mu \mathrm{g})$ by incubating the serum and beads together for $15 \mathrm{~min}$ at $23^{\circ} \mathrm{C}$. The conjugated beads were washed and then incubated with BAE CM $(500 \mu \mathrm{l} ; A)$ or platelet releasate $\left(200 \mu \mathrm{l}\right.$, representing $4 \times 10^{8}$ platelets; $B$ ) for $1 \mathrm{~h}$. The beads were collected by centrifugation, washed, extracted with sample buffer, and the respective extracts $(25 \mu l$, lane $3)$, supernatants ( $50 \mu \mathrm{l}$, lane 2$)$, and starting materials ( $50 \mu \mathrm{l}$, lane 1$)$ were analyzed by RFA. The indicator film was photographed after 2-h incubation at $37^{\circ} \mathrm{C}$. by RFA. In both cases, virtually all of the inhibitor activity was immunoprecipitated with the antiserum with little or no detectable activity remaining in the supernatant. Nonimmune serum did not immunoprecipitate significant inhibitor activity in either case (not shown). Thus, the BAE and platelet inhibitors not only comigrate but appear to be immunologically related since both are recognized by the same antiserum.

This antiserum was then employed to examine whether the anti-PA activity detected in platelet releasate (Fig. 6) resulted from the inhibitor detected by RFA (Fig. 2). Platelet releasate was passed over an immunoadsorbent column containing the IgG fraction of the anti-BAE inhibitor serum. Each of the resulting fractions was then assayed by RFA (Fig. 8). The composite shown in the left panel demonstrates that all of the inhibitor activity in the starting material (lane 1) was removed from the releasate (lane 2) and recovered in the eluted material (lane 3). In addition, all of the time-dependent anti-t-PA activity was similarly removed and recovered as measured in the ${ }^{125}$ I-fibrin plate assay (Fig. 8, right). Similar results were obtained when these samples were assayed for anti-urokinase activity (data not shown). Collectively, these results suggest that the inhibitors detected by RFA in BAE
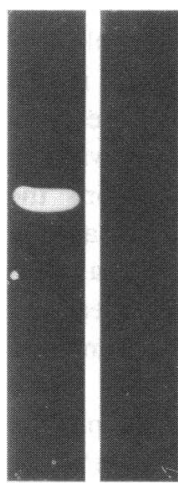
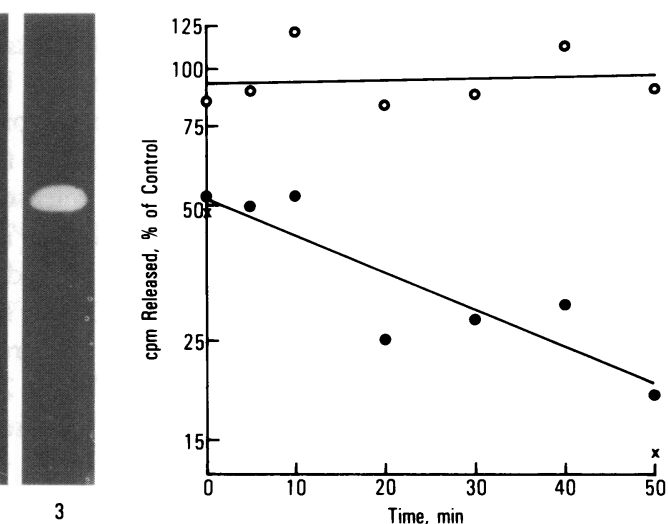

Figure 8. Anti-PA activity in immunoadsorbed platelet samples. The IgG from antiserum against the BAE inhibitor was purified and coupled to $\mathrm{CNBr}$-activated Sepharose and an immunoadsorbent column was prepared as described in Methods. Platelet releasate (165 $\mathrm{ml}$, representing $3.3 \times 10^{11}$ platelets) was applied to the column, which was washed and then eluted with $3 \mathrm{M} \mathrm{MgCl}_{2}$. The starting releasate ( $50 \mu \mathrm{l}$, lane 1$)$, the material that did not bind to the column $(50 \mu \mathrm{l}$, lane 2), and the material eluted from the column $(5 \mu \mathrm{l}$, lane 3) were analyzed by RFA (left). These same samples were assessed for anti-PA activity in the ${ }^{125}$ I-fibrin plate assay (right). In this case, the samples were preincubated with t-PA for various times, and the effect of this preincubation on the extent of inhibition was determined. The residual fibrinolytic activity in mixtures containing the starting platelet releasate $(25 \mu \mathrm{l}, \bullet)$, the run-through from the column $(25 \mu \mathrm{l}, \mathrm{O})$, or the material eluted from the column $(15 \mu \mathrm{l}, \times)$ was then determined and expressed as a percentage of the activity present in samples preincubated with buffer only. 
$\mathrm{CM}$ and human platelet releasate are immunologically related, and that the anti-PA activity detected in the platelet releasate is at least partially attributable to this inhibitor.

\section{Discussion}

A number of investigators have detected antifibrinolytic activity (both antiplasmin and anti-PA) in platelets (reviewed in 29, 30). However, most of the components responsible for these "activities" remain poorly characterized in that they have not been purified, their activity towards t-PA is not known, and it is not clear whether they are actually platelet-derived or simply represent contaminating plasma constituents. The existence of an anti-t-PA activity within platelets, one which is released by normal stimuli, would suggest that the environment of a vessel occluded by a fibrin-platelet thrombus might be quite inhibitory, and thus potentially refractory to thrombolytic therapy by t-PA (31).

We previously employed RFA to detect a number of SDSstable fibrinolytic inhibitors in bovine serum (13). The major inhibitor had an apparent molecular weight of 50,000. Here, we show that an inhibitor of similar molecular weight is also present in human serum (Fig. 1). This inhibitor was not detected in PPP serum suggesting that it originated from the platelets themselves, and was not a contaminating plasma/ serum protein. These conclusions are supported by the results shown in Figs. 1 and 2 which demonstrate the presence of an inhibitor of similar molecular weight in extracts from washed, gel-filtered platelets. The inhibitor was released from the platelets by physiological levels of thrombin (Fig. 2) and in parallel with the release of PF-4 (Figs. 3 and 4), a wellcharacterized platelet $\alpha$-granule protein (32). The release of both of these components was blocked by pretreating the platelets with $\mathrm{PGE}_{1}$ and theophylline (Figs. 2 and 3), a procedure known to interfere with the release of platelet granule proteins (33). Although the inhibitor may also be present in other cells found in the blood, these observations suggest that the inhibitor, like PF-4, is a platelet protein probably released during platelet aggregation and thrombus formation.

The platelet releasates inhibited both t-PA and urokinasemediated fibrinolytic activity (Fig. 5). Preincubation of releasate with either of these PAs increased the amount of inhibition in a time-dependent manner (Fig. 6), suggesting that this antifibrinolytic activity resulted, at least in part, from the presence of a molecule(s) acting directly on the PA (i.e., an antiactivator). Interestingly, the inhibitor detected in platelet releasates by RFA had a molecular weight similar to an inhibitor produced by cultured BAEs $(12,20)$, and was in fact immunologically related since antiserum to the BAE inhibitor recognized the human platelet inhibitor (Fig. 7). Moreover, passage of platelet releasate through an anti-BAE inhibitor immunoadsorbent column (Fig. 8) removed the component(s) responsible for both the lysis-resistant zone detected by RFA (Fig. 2) and the time-dependent anti-PA activity demonstrated in Fig. 6. Both inhibitor activities were recovered in the eluant from this column. These results indicate that the time-dependent antiPA activity of platelet releasate results from a single inhibitor having an apparent molecular weight of 50,000. Inhibition of t-PA by the purified BAE inhibitor is associated with the formation of an SDS-stable, enzyme-inhibitor complex (34), indicating that it does not act by proteolytically degrading the t-PA. Because the platelet and BAE inhibitors are immunologically similar, it is likely that they neutralize t-PA in a similar manner.

Several investigators have reported that platelets contain antiplasmin activity (see 29, 30 for review), including $\alpha_{2}$-antiplasmin (35). Our inability to detect significant levels of antiplasmin activity in releasates may reflect the relatively low concentrations of such activity actually present $(\sim 60 \mathrm{ng}$ of $\alpha_{2}$-antiplasmin $/ 10^{9}$ platelets) (35). It is not clear whether the small amount of antiplasmin activity that we did detect was caused by the antiactivator, by $\alpha_{2}$-antiplasmin, or by one of the other antiplasmins present $(27,28)$. In any case, our findings suggest that the major antifibrinolytic activity in platelet releasates is directed against PA.

The activity of most serine proteinases is regulated by specific inhibitors $(36,37)$. However, the issue of whether such an inhibitor also regulates the activity of t-PA remains controversial. For example, Heimberger (38) and Hedner (39) reviewed the properties of the known protease inhibitors present in human plasma and concluded that none had anti-PA activity. In addition, although Korninger and Collen (8) detected antit-PAs in plasma, they were slow-acting and because of this judged not to be of physiologic significance. In contrast to these results, more recent studies suggest the presence of a fast-acting inhibitor of t-PA in certain plasmas $(10,11)$. These apparently disparate results may be explained by differences in assays or, alternatively, may reflect variations in the plasma itself. Thus, inhibitor-rich plasmas were collected from patients with various hemostatic abnormalities $(10,11)$, whereas inhibitor-poor plasmas were collected from "normal" donors (8). Whether these results reflect differential release of inhibitor(s) from platelets and/or other cells in vivo, or during the processing of the blood, cannot be determined from the published data.

In summary, the results presented here suggest that human platelets contain and release an inhibitor of both urokinase and tissue-type PA. This inhibitor is immunologically related to an inhibitor of similar molecular weight and specificity found in BAEs $(12,20)$. The unusual stability of this latter molecule (12) suggests that it is not protease-nexin (40) (Erickson, L. A., M. H. Ginsberg, and D. J. Loskutoff, unpublished observations) or any of the known plasma protease inhibitors $(31,32)$. We have detected an inhibitor of similar molecular weight in samples obtained from a number of other vascular 
and nonvascular cells (data not shown), suggesting that the inhibitor may be important both within and outside of the vascular system. Elucidation of the distribution, the mechanism of action, and the regulation of this inhibitor will add considerably to our understanding of the control of the fibrinolytic system.

\section{Acknowledgments}

The authors acknowledge the excellent technical assistance of $\mathrm{K}$ Roegner and D. Dixon, and thank G. Josephs for typing the manuscript.

This work was supported in part by a grant from Eli Lilly and Co., and by National Institutes of Health grants HL22289 and HL16411 to Dr. Loskutoff, by AM27214 to Dr. Ginsberg, and by a fellowship to Dr. Erickson from the California Affiliate of the American Heart Association.

\section{References}

1. Collen, D. 1980. On the regulation and control of fibrinolysis. Thromb. Haemostasis. 43:77-89.

2. Rijken, D. C., G. Wijngaards, and J. Welbergen. 1981. Immunological characterization of plasminogen activator activities in human tissues and body fluids. J. Lab. Clin. Med. 97:477-486.

3. Wiman, B., G. Mellbring, and M. Rånby. 1983. Plasminogen activator release during venous stasis and exercise as determined by a new specific assay. Clin. Chim. Acta. 127:279-288.

4. Hoylaerts, M., D. C. Rijken, H. R. Lijnen, and D. Collen. 1982. Kinetics of the activation of plasminogen by human tissue plasminogen activator. Role of fibrin. J. Biol. Chem. 257(6):2912-2919.

5. Loskutoff, D. J., and L. Mussoni. 1983. Interactions between fibrin and the plasminogen activators produced by cultured endothelial cells. Blood. 62(1):62-68.

6. Lijnen, H. R., and D. Collen. 1982. Interaction of plasminogen activators and inhibitors with plasminogen and fibrin. Sem. Thromb. Haemostasis. 8(1):2-10.

7. Wiman, B., and D. Collen. 1977. Purification and characterization of human antiplasmin, the fast-acting plasmin inhibitor in plasma. Eur. J. Biochem. 78:19-26.

8. Korninger C., and D. Collen. 1981. Neutralization of human extrinsic (tissue-type) plasminogen activator in human plasma: no evidence for a specific inhibitor. Thromb. Haemostasis. 46:662-665.

9. Walker, J. E., L. Gow, D. M. Campbell, and D. Ogston. 1983. The inhibition by plasma of urokinase and tissue activator-induced fibrinolysis in pregnancy and the puerperium. Thromb. Haemostasis. 29(1):21-23.

10. Kruithof, E. K. O., A. Ransijn, and F. Bachmann. 1983. Inhibition of tissue plasminogen activator by human plasma. Prog. Fibrinolysis. 6:362-366.

11. Chmielewska, J., M. Rånby, and B. Wiman. 1983. Evidence for a rapid inhibitor to tissue plasminogen activator in plasma. Thromb. Res. 31:427-436.

12. Loskutoff, D. J., J. A. van Mourik, L. A. Erickson, and D. Lawrence. 1983. Detection of an unusually stable fibrinolytic inhibitor produced by bovine endothelial cells. Proc. Natl. Acad. Sci. USA. 80:2956-2960.
13. Erickson, L. A., D. A. Lawrence, and D. J. Loskutoff. 1984. Reverse fibrin autography: a method to detect and partially characterize protease inhibitors after sodium dodecyl sulfate-polyacrylamide gel electrophoresis. Anal. Biochem. 137:454-463.

14. Ginsberg, M. H., L. Taylor, and R. G. Painter. 1980. The mechanism of thrombin-induced platelet factor 4 secretion. Blood. 55:661-670.

15. Loskutoff, D. J. 1979. Effect of thrombin on the fibrinolytic activity of cultured bovine endothelial cells. J. Clin. Invest. 64:329332.

16. Levin, E. G., and D. J. Loskutoff. 1982. Cultured bovine endothelial cells produce both urokinase and tissue-type plasminogen activators. J. Cell Biol. 94:631-636.

17. Laemmli, U. K. 1970. Cleavage of structural proteins during the assembly of the head of bacteriophage $T_{4}$. Nature (Lond.). 227:680685 .

18. Unkeless, J. C., A. Tobia, L. Ossowski, J. P. Quigley, D. B. Rifkin, and E. Reich. 1973. An enzymatic function associated with transformation of fibroblasts by oncogenic viruses. I. Chick embryo fibroblast cultures transformed by avian RNA viruses. J. Exp. Med. 137:85-111.

19. Loskutoff, D. J., and T. S. Edgington. 1977. Synthesis of a fibrinolytic activator and inhibitor by endothelial cells. Proc. Natl. Acad. Sci. USA. 74(9):3903-3907.

20. van Mourik, J. A., D. A. Lawrence, and D. J. Loskutoff. 1983. Characterization of a novel fibrinolytic inhibitor synthesized by bovine aortic endothelial cells in culture. Thromb. Haemostasis. 50:281. (Abstr.)

21. van Eijk, H. G., and W. L. van Noort. 1976. Isolation of rat transferrin using CNBr-activated Sepharose 4B. J. Clin. Chem. Clin. Biochem. 14:475-478.

22. Ginsberg, M. H., R. Hoskins, P. Sigrist, and R. G. Painter. 1979. Purification of a heparin-neutralizing protein from rabbit platelets and its homology with human platelet factor 4. J. Biol. Chem. 254:12365-12371.

23. Deutsch, D. G., and E. T. Mertz. 1970. Plasminogen: purification from human plasma by affinity chromatography. Science (Wash. DC). 170:1095-1096.

24. Rijken, D. C., and D. Collen. 1981. Purification and characterization of the plasminogen activator secreted by human melanoma cells in culture. J. Biol. Chem. 256:7035-7041.

25. Brewer, J. M., A. J. Pesce, and R. B. Ashworth. 1974. Experimental Techniques in Biochemistry. Prentice-Hall, Inc., Englewood Cliffs, NJ. 1-374.

26. Moore, S., D. S. Pepper, and J. D. Cash. 1975. The isolation and characterisation of a platelet-specific $\beta$-globulin ( $\beta$-thromboglobulin) and the detection of antiurokinase and antiplasmin released from thrombin-aggregated washed human platelets. Biochim. Biophys. Acta. 379:360-369.

27. Joist, J. H., S. Niewiarowski, N. Nath, and J. F. Mustard. 1976. Platelet antiplasmin: its extrusion during the release reaction, subcellular localization, characterization, and relationship to antiheparin in pig platelets. J. Lab. Clin. Med. 87(4):659-669.

23. Hansen, M. S., and I. Clemmensen. 1980. Partial purification and characterization of a new fast-acting plasmin inhibitor from human platelets. Biochem. J. 187:173-180.

29. Thorsen, S., P. Brakman, and T. Astrup. 1972. Influence of platelets on fibrinolysis: a critical review. Hematol. Rev. 3:123-179. 
30. Joist, J. H. 1977. Platelets and fibrinolysis. Thromb. Haemostasis. 38:955-962.

31. Matsuo, O., D. C. Rijken, and D. Collen. 1981. Thrombolysis by human tissue plasminogen activator and urokinase in rabbits with experimental pulmonary embolus. Nature (Lond.). 291:590-591.

32. Walsh, P. N., and G. Gagnatelli. 1974. Platelet antiheparin activity: storage site and release mechanism. Blood. 44(2):157-168.

33. Packham, M. A. 1983. Platelet function inhibitors. Thromb. Haemostasis. 50(2):610-619.

34. Loskutoff, D. J. 1984. The fibrinolytic system of cultured endothelial cells: deciphering the balance between plasminogen activation and inhibition. Prog. Fibrinolysis. In press.

35. Plow, E. F., and D. Collen. 1981. The presence and release of $\alpha_{2}$-antiplasmin from human platelets. Blood. 58(6):1069-1074.

36. Laskowski, M., Jr., and I. Kato. 1980. Protein inhibitors of proteinases. Ann. Rev. Biochem. 49:593-626.
37. Travis, J., and G. S. Salvesen. 1983. Human plasma proteinase inhibitors. Ann. Rev. Biochem. 52:655-709.

38. Heimburger, N. 1975. Proteinase inhibitors of human plasmatheir properties and control functions. In Proteases and Biological Control. E. Reich, D. B. Rifkin, and E. Shaw, editors. Cold Spring Harbor Laboratory, Cold Spring Harbor, NY. 367-386.

39. Hedner U. 1979. Inhibitor(s) of plasminogen activation distinct from the other plasma protease inhibitors-a review. In The Physiological Inhibitors of Coagulation and Fibrinolysis. D. Collen, B. Wiman, and M. Verstraete, editors. Elsevier/North-Holland, Amsterdam. 189-197.

40. Baker, J. B., D. A. Low, R. L. Simmer, and D. D. Cunningham. 1980. Protease-nexin: a cellular component that links thrombin and plasminogen activator and mediates their binding to cells. Cell. 21: $37-45$. 